\title{
Kaposi Sarcoma
}

National Cancer Institute

\section{Source}

National Cancer Institute. Kaposi Sarcoma. NCI Thesaurus. Code C9087.

A malignant neoplasm characterized by a vascular proliferation which usually contains blunt endothelial cells. Erythrocyte extravasation and hemosiderin deposition are frequently present. The most frequent site of involvement is the skin; however it may also occur internally. It generally develops in people with compromised immune systems including those with acquired immune deficiency syndrome (AIDS). 